УДК $54.055+547.596 .4$

\title{
ФИЗИКО-ХИМИЧЕСКИЕ ЗАКОНОМЕРНОСТИ ПОЛУЧЕНИЯ МОНОТЕРПЕНОВЫХ СПИРТОВ И ОЦЕНКА ИХ БИОЛОГИЧЕСКОЙ
} АКТИВНОСТИ

\author{
() А.Б. Радбиль, Т.И. Долинский, А.С. Новоселов, Е.А. Маврина, А.А. Шалашова, И.С. Ильичев, \\ А.В. Сулимов", В.Ф. Смирнов, О.Н. Смирнова \\ Нижегородский государственный университет им. Н.И. Лобачевского, \\ пр. Гагарина, 23, Нижний Новгород, 603950 (Россия), e-mail: asulimov@mail.ru
}

Изучены химические основы синтеза монотерпеновых спиртов гидратацией скипидара при катализе ортофосфорной кислотой. Рассмотрено влияние концентрации катализатора, водного модуля, температуры и продолжительности гидратации на состав и количество получаемых продуктов. Рекомендованы условия получения монотерпеновых спиртов: концентрация водного раствора катализатора - 40\%, температура - $65{ }^{\circ} \mathrm{C}$, продолжительность синтеза - 4 ч, водный модуль $-1: 1$, количество эмульгатора $-0,3 \%$ от объема ортофосфорной кислоты. Изучена кристаллизации $\alpha$ терпинеола из реакционных смесей с высоким содержанием терпеновых спиртов. Определены основные физикохимические характеристики получаемых продуктов и проведено исследование их фунгицидной и бактерицидной активности.

Ключевые слова: скипидар, $\alpha$-пинен, $\alpha$-терпинеол, гидратация, катализ.

Работа выполнена в Нижегородском государственном университете им. Н.И. Лобачевского при финансовой поддержке Министерства образования и науки РФ (договор № 02.G25.31.0073).

\section{Введение}

Вектор современного развития химической промышленности, наряду с использованием традиционного углеводородного сырья, все больше направлен на использование биоресурсов растительного проис-

Радбиль Аркадий Беньюминович - заведующий лабораторией лесохимии, доктор технических наук, e-mail: a.radbil@orgkhim.com

Долинский Тарас Иванович - младший научный сотрудник, e-mail: t.dolinski@orgkhim.com

Новоселов Артем Сергеевич - младший научный сотрудник, e-mail: a.novoselov@orgkhim.com

Маврина Екатерина Александровна - аспирант, e-mail: ekaterina.mawrina@yandex.ru

Шалашова Александра Аркадьевна - младший научный сотрудник, e-mail: aleksa-a1989@mail.ru

Ильичев Илья Сергеевич - старший научный сотрудник, кандидат химических наук, e-mail: i.ilichev@ orgkhim.com Сулимов Александр Владимирович - старший научный сотрудник, доктор технических наук, доцент, e-mail: asulimov@ mail.ru

Смирнов Василий Филиппович - старший научный сотрудник, доктор биологических наук, профессор, e-mail: biodeg@mail.ru

Смирнова Ольга Николаевна - старший научный сотрудник, кандидат биологических наук, доцент, e-mail: biodeg@mail.ru хождения. Уникальная особенность растительной биомассы состоит в том, что это возобновляемый источник органического сырья, квалифицированное использование которого демонстрирует устойчивый тренд роста. Российская Федерация является крупнейшей в мире лесной державой, где произрастает около половины мировых запасов хвойных деревьев [1]. Все они продуцируют смолистые вещества, представляющие собой сложную смесь монотерпенов и дитерпеноидов. Летучая часть смолистых веществ, которую принято называть скипидаром, состоит в основном из монотерпеновых углеводородов общей формулой $\mathrm{C}_{10} \mathrm{H}_{16}$ и, как правило, содержит небольшие примеси сесквитерпенов и кислородержащих производных терпенов. Присутствие в структуре монотерпеновых углеводородов двойных связей и мос-

\footnotetext{
* Автор, с которым следует вести переписку.
} 
тиковых циклических структур определяет их реакционную способность: им свойственны реакции присоединения, алкилирования, изомеризации, полимеризации и др. Благодаря этому скипидар является уникальным сырьем для получения многих экологически чистых продуктов, которые могут применяться в самых различных областях народного хозяйства. В последние десятилетия активно развиваются технологии окислительно-восстановительной [2] и кислотно-основной трансформации [3, 4] углеводов древесины, разрабатываются методы комплексного использования всех основных компонентов древесной биомассы [5]. При этом спектр получаемых продуктов весьма широк и охватывает медицинскую, фармацевтическую, парфюмерно-косметическую, пищевую, химическую отрасли, сельское хозяйство и бытовую химию. В связи с этим разработка высокоэффективных, экологически чистых и ресурсосберегающих отечественных технологий глубокой переработки скипидара является актуальной и весьма своевременной задачей.

Одним из наиболее перспективных направлений переработки скипидара является его кислотнокаталитическая гидратация, приводящая к образованию разнообразных кислородсодержащих производных монотерпеновых углеводородов, важное практическое значение среди которых имеют смеси монотерпеновых одноатомных спиртов с преобладающим содержанием $\alpha$-терпинеола (сосновое масло), проявляющие ярко выраженную биологическую активность. Известные способы получения этих целевых продуктов путем гидратации $\alpha$-пинена и скипидара, катализируемой серной кислотой, в настоящее время достаточно хорошо изучены и имеют ряд существенных недостатков [6-10], к числу которых можно отнести высокую коррозионную активность реакционной среды, необходимость утилизации больших объемов разбавленной кислоты и пр. Ранее проведенные нами исследования $[11,12]$ показали, что наряду с серной кислотой эффективными катализаторами процесса являются $\mathrm{HClO}_{4}, \mathrm{H}_{3} \mathrm{PW}_{12} \mathrm{O}_{40}, \mathrm{H}_{4} \mathrm{SiW}_{12} \mathrm{O}_{40}$. Однако, несмотря на высокую эффективность данных кислотных катализаторов, их использование в промышленных условиях представляется весьма ограниченным. Так, например, вольфрамовые гетерополикислоты структуры Кеггина, в которых в качестве центрального атома выступает атом кремния или фосфора, имеют очень высокую стоимость и их использование в качестве катализаторов гидратации не оправдывает себя в экономическом плане. В то время как хлорная кислота, хоть и является весьма сильной минеральной кислотой, но присутствие хлора в высшей степени окисления предопределяет ее окислительные свойства, кроме того, она может приводить к образованию хлорорганических соединений, присутствие которых в товарных продуктах является крайне нежелательным. В этой связи представляется весьма перспективным исследование каталитических свойств ортофосфорной кислоты в рассматриваемом процессе. Цель данной работы заключалась в исследовании физико-химических основ кислотно-каталитической гидратации скипидара в присутствии ортофосфорной кислоты с образованием монотерпеновых спиртов и оценке биоцидной активности получаемых продуктов.

\section{Экспериментальная часть}

Объектом исследования в данной работе являлся скипидар сульфатный очищенный, содержание $\alpha$-пинена 95\% ТУ 2416-010-80255613-2007 (ОАО «Группа "Илим"», филиал в Усть-Илимске).

Процесс вели в гетерогенных жидкофазных условиях с перемешиванием реакционной массы. Для увеличения поверхности контакта двух несмешивающихся жидких фаз использовали эмульгатор - катамин АБ. Лабораторная установка для проведения процессов состояла из стеклянного реактора, снабженного рубашкой для обогрева и нижним сливом, обратным холодильником, термометром и перемешивающим устройством с регулируемым числом оборотов. Температуру в реакторе поддерживали в интервале 30-80 ${ }^{\circ} \mathrm{C}$ путем циркуляции воды от термостата через рубашку аппарата.

В реактор при комнатной температуре помещали расчетные количества скипидара, водного раствора катализатора требуемой концентрации и эмульгатора. Включали перемешивающее устройство с фиксированным числом оборотов, нагревали реакционную массу до заданной температуры и вели перемешивание в течение определенного времени. По окончании процесса реакционную массу из реактора через фильтрующее устройство (для отделения образующегося терпингидрата) направляли в делительную воронку для отстаивания, после чего отделяли верхний слой, представляющий собой смесь жидких продуктов реакции, от нижнего слоя - водного раствора катализатора. Смесь продуктов реакции обрабатывали $10 \%$-м водным 
раствором $\mathrm{NaOH}$ для нейтрализации остатка катализатора. Избыток $\mathrm{NaOH}$ отмывали горячей дистиллированной водой. Далее смесь продуктов реакции ректифицировали в насадочной ректификационной колонне диаметром 39 мм, эффективностью по смеси бензол-дихлорэтан 30 теоретических тарелок при остаточном давлении 2 кПа и флегмовом числе 5-6, последовательно собирая в качестве товарных продуктов фракцию монотерпеновых углеводородов (МУВ) до температуры $130{ }^{\circ} \mathrm{C}$ и фракцию монотерпеновых спиртов (МС) в интервале температур $130-150^{\circ} \mathrm{C}$. Далее в отогнанных фракциях методом ГЖХ определяли состав компонентов. Кубовой остаток после ректификации представлял собой политерпены.

Количественный и качественный состав продуктов реакции анализировали на хроматографе «Кристаллюкс $4000 \mathrm{M»,} \mathrm{снабженном} \mathrm{пламенно-ионизационным} \mathrm{детектором} \mathrm{и} \mathrm{капиллярной} \mathrm{колонкой} \mathrm{ZB-1} \mathrm{(ди-}$ метилполисилоксан, длина - 30 м, диаметр - 0,25 мм, 0,25 мкм). В качестве газа носителя использовали азот. Идентификацию продуктов в реакционной смеси вели с использованием эталонных соединений и по индексам относительного удерживания терпеноидов согласно [13]. Расчет количества компонентов реакционной смеси осуществляли методом нормировки площадей пиков [14].

Определение цветности жидких продуктов гидратации проводили на автоматическом спектрофотометрическом колориметре для жидких химических продуктов Lovibond cep. PFXi 195. Для измерений использовали кювету, имеющую оптический путь L 50 мм.

Оценку плотностей получаемых продуктов осуществляли с использованием ареометров в соответствии с ГОСТ 3900-85. Определение показателей преломления терпеновых спиртов и $\alpha$-терпинеола проводили на рефрактометре ИРФ-454Б2М в соответствии с ГОСТ 5482-90. Температуру застывания $\alpha$-терпинеола определяли согласно ГОСТ 20287-91 на лабораторном автоматическом приборе для определения температуры застывания и текучести нефтепродуктов ЛАЗ-М.

Для оценки бактерицидной и фунгицидной активности был использован метод бумажных дисков. Бумажные диски ( $\mathrm{d}=6$ мм) пропитывали сосновым маслом и раствором $\alpha$-терпинеола в толуоле (5 и $10 \%$ растворы) и помещали на поверхность агаризованной среды в чашках Петри [15]. В качестве тест-культур использовались следующие виды: микромицетов, относящихся к разным систематическим группам: Aspergillus niger, A. amstelodami, Penicillium chrysogenum и дрожжеподобный гриб Candida albicans и бактерий: Staphylococcus aureus, Pseudomonas aeruginosa, Staphylococcus epidermidis, Escherichia coli.

Продолжительность испытаний на фунгицидность составляла 14 суток (для Candida albicans - 48-72 ч) при температуре $29^{\circ} \mathrm{C}$ и влажности более $90 \%$. Продолжительность испытаний на бактерицидность составляла $24-48$ ч при температуре $37^{\circ} \mathrm{C}$.

\section{Обсуждение результатов}

Кислотно-каталитическое присоединение к монотерпеновым углеводородам воды, спиртов, карбоновых кислот и некоторых других классов соединений является одним из широко распространенных типов реакций, положенных в основу целевого получения вторичных скипидарных продуктов. Такие процессы относятся к реакциям электрофильного присоединения по ненасыщенным связям.

Характерной особенностью реакций электрофильного присоединения к монотерпеновым углеводородам, главным образом к бициклическим, является сопровождающее реакцию изменение углеродного скелета, происходящее вследствие разрывов цикла или перегруппировок, протекающих через большое число последовательных перестроек углеродного скелета $[16,17]$. Содержание каждого из продуктов гидратации $\alpha$-пинена в реакционной смеси, суммарное количество спиртов, углеводородов и их димеров, а также соотношение между монотерпеноидами моно- и бициклического строения существенным образом зависит от условий проведения процесса.

В ходе экспериментального исследования физико-химических закономерностей получения монотерпеновых спиртов гидратацией скипидара в присутствии ортофосфорной кислоты было изучено влияние концентрации катализатора, водного модуля, температуры и продолжительности гидратации. Методом ГЖХ было установлено, что в результате гидратации скипидара при катализе $\mathrm{H}_{3} \mathrm{PO}_{4}$, образуются следующие монотерпеновые соединения: углеводороды - камфен, трициклен, дипентен, $\alpha$ - и $\gamma$-терпинен, терпинолен, изотерпинолен, $n$-цимол, $n$-ментен-3; спирты - $\alpha$-, $\beta$ - и $\gamma$-терпинеол, терпиненол- 4 , терпиненол- 1 , 
борнеол, изоборнеол; и в незначительных количествах эфиры: 1,8- и 1,4-цинеол; кристаллогидрат 1,8терпина (терпингидрат); а также политерпены.

Анализ полученных данных показал, что зависимость массовой доли МС как от концентрации катализатора (рис. 1), так и от температуры процесса (рис. 2) носит экстремальный характер с максимумом содержания МС около 40\%, соответствующим ведению процесса гидратации в течение 4 ч при температуре $65^{\circ} \mathrm{C}$ в присутствии 40\%-го водного раствора ортофосфорной кислоты и модуле $1: 1$. Содержание же МУВ с повышением концентрации катализатора и температуры гидратации монотонно возрастает. Наряду с этим в реакционной смеси происходит появление и дальнейшее накопление политерпенов.

Как показывают кинетические данные, в первые 3 ч преобладает направление реакции, приводящее к образованию МC (рис. 3). Дальнейшее увеличение продолжительности процесса гидратации $\alpha$-пинена в присутствии 42\%-го водного раствора ортофосфорной кислоты при температуре $65{ }^{\circ} \mathrm{C}$ с 4 до 8 ч приводит к росту в продуктах гидратации только МУВ за счет продолжающейся в данных условиях изомериза-

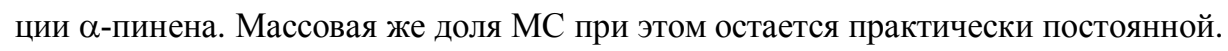

При одинаковой концентрации катализатора в тех же условиях было изучено влияние соотношения органической и водной фракций в реакционной смеси на скорость реакции гидратации. С этой целью была проведена серия экспериментов при постоянном количестве водной фазы и возрастающем содержании органической фазы. В ходе исследования было установлено, что увеличение доли органической фазы по отношению к водному раствору ортофосфорной кислоты приводит к заметному снижению скорости гидратации (рис. 4).

Таким образом, на базе обобщения полученных данных было установлено, что для получения МС

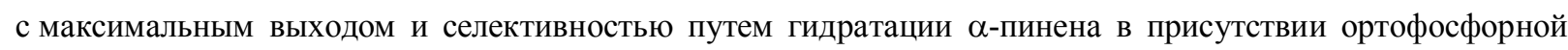
кислоты наиболее целесообразными условиями являются: концентрация водного раствора катализатора $40 \%$, температура $-65^{\circ} \mathrm{C}$, продолжительность синтеза -4 ч, водный модуль $-1: 1$, количество эмульгатора $-0,3 \%$ от объема ортофосфорной кислоты.

Следует отметить, что четырехкратное повторное использование 40\%-го водного раствора ортофосфорной кислоты в качестве катализатора гидратации $\alpha$-пинена не оказывает заметного влияния на состав продуктов реакции.

Для выделения смеси терпеновых спиртов реакционную массу (39,9 МС и 42,6 масс.\% МУВ), полученную путем гидратации скипидара в рекомендованных выше условиях, после подвергали вакуумректификации. При этом выход МС от суммы пиненов, взятых на реакцию, составил 41,2\%. Состав выделенной фракции и ее физико-химические свойства представлены в таблице 1.

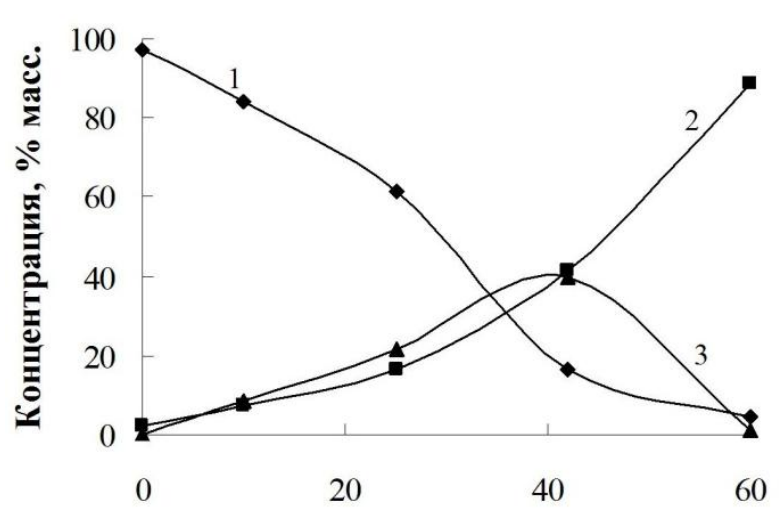

Концентрация водного раствора катализатора, \% масс.

Рис. 1. Зависимость состава продуктов гидратации $\alpha$-пинена от концентрации водного раствора $\mathrm{H}_{3} \mathrm{PO}_{4}$ (температура $65{ }^{\circ} \mathrm{C}$, длительность синтеза 4 ч, модуль $1: 1,0,3$ об. \% эмульг. от катал.) 1 - $\alpha$-пинен; 2 - МУВ; 3 - МС

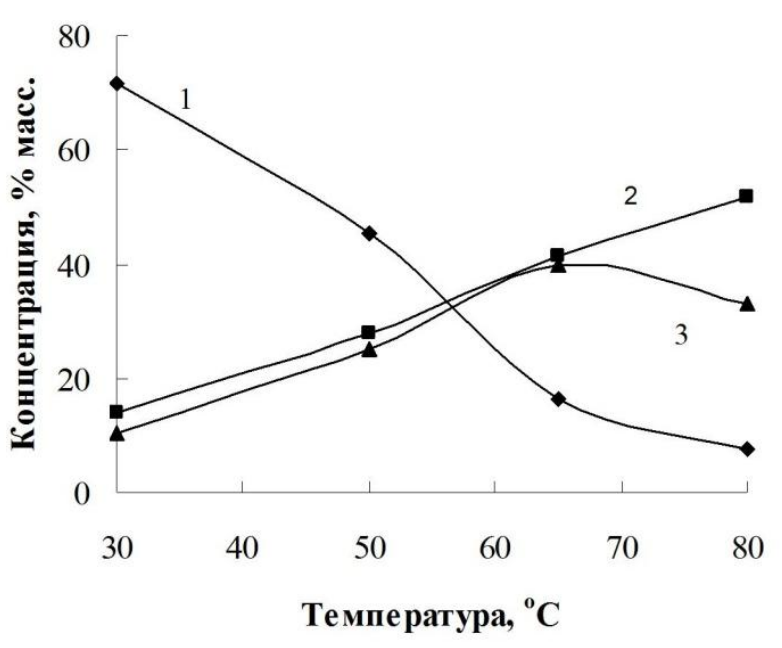

Рис. 2. Зависимость состава продуктов гидратации $\alpha$-пинена от температуры синтеза (концентрация водного раствора катализатора $42 \%$ (масс.), длительность синтеза 4 ч, модуль $1: 1,0,3$ об. \% эмульг. от катал.) 1 - $\alpha$-пинен; 2 - МУВ; 3 - МС 


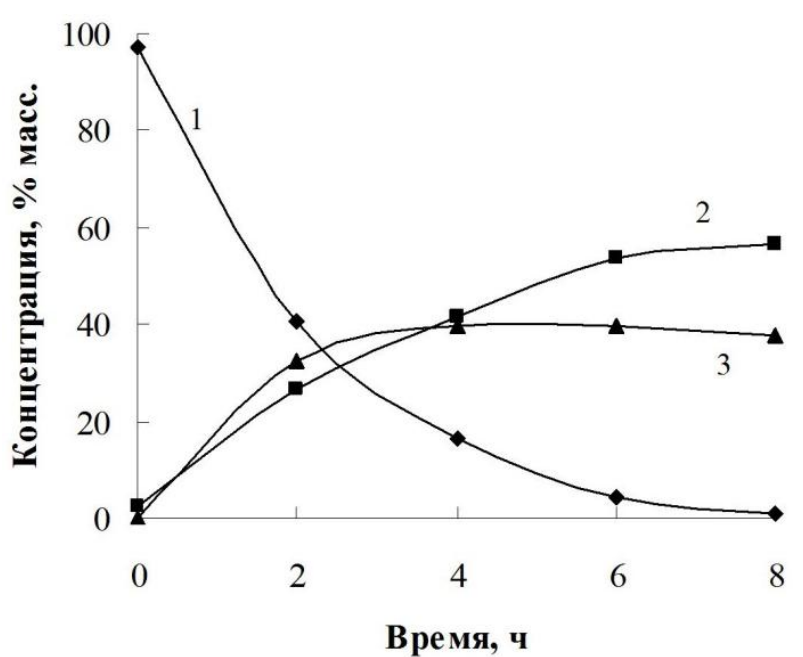

Рис. 3. Зависимость состава продуктов гидратации

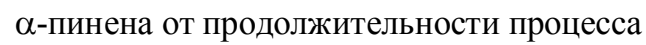
(концентрация водного раствора катализатора $42 \%$ (масс.), температура $65^{\circ} \mathrm{C}$, модуль $1: 1,0,3$ об. \% эмульгатора от катализатора) $1-\alpha$-пинен; 2 - МУВ; 3 - МС

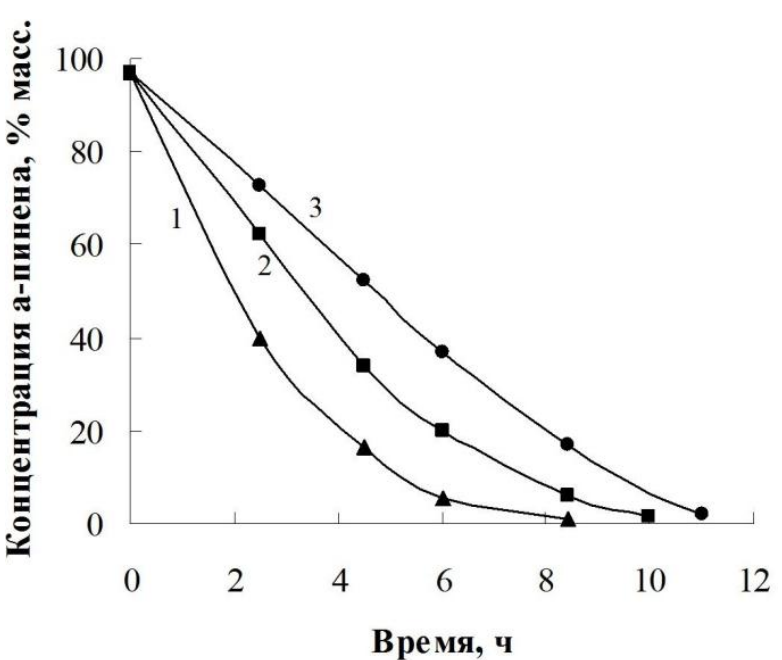

Рис. 4. Зависимость концентрации $\alpha$-пинена от продолжительности процесса при различных начальных соотношениях водный раствор : скипидар. (концентрация водного раствора катализатора $42 \%$ (масс.), температура $65^{\circ} \mathrm{C}$, 0,3 об.\% эмульгатора от катализатора).

1 - соотношение водный раствор : скипидар - 1,0 : 1,$0 ; 2$ - соотношение водный раствор : скипидар $1,0: 1,3 ; 3$ - соотношение водный раствор : скипидар - 1,0 : 1,5

Таблица 1. Физико-химические свойства фракции терпеновых спиртов

\begin{tabular}{l|c}
\hline \multicolumn{1}{c}{ Наименование показателя } & 3начение показателя \\
\hline Показатель цветности по Хазену, $\mathrm{L}=50$ мм, $\mathrm{mgPt} / \mathrm{J}$ & 46,5 \\
Плотность при $20^{\circ} \mathrm{C}$, г $/ \mathrm{cm}^{3}$ & 0,944 \\
Показатель преломления при $20^{\circ} \mathrm{C}$ & 1,4837 \\
Массовая доля (ГЖХ), $\%$ & \\
сумма терпеновых углеводородов, & 3,3 \\
сумма терпеновых спиртов, в том числе, & 96,4 \\
$\alpha$-терпинеол & 80,0 \\
$\beta$-терпинеол & 2,1 \\
терпиненол-4 & 9,4 \\
$\gamma$-терпинеол & 0,5 \\
терпиненол-1 & 0,5 \\
борнеол & 0,5 \\
изоборнеол & 3,4 \\
\hline
\end{tabular}

Анализ данных, представленных в таблице 1, показал, что выделенная фракция (сосновое масло) имеет высокое содержание терпеновых спиртов - 96,4 масс.\%. Кроме того, обращает внимание и значительное количество $\alpha$-терпинеола в полученном продукте. Из литературных источников [18] известно, что при охлаждении соснового масла с высоким содержанием $\alpha$-терпинеола наблюдается его кристаллизация. В рамках оценки возможности выделения $\alpha$-терпинеола из отогнанной фракции монотерпеновых спиртов были проведены экспериментальные исследования температурного режима его кристаллизации. В ходе исследования контролировали количество выделенного продукта и температуру его застывания. Полученные результаты представлены в таблице 2.

Как видно из данных таблицы 2, количество выделяемого $\alpha$-терпинеола возрастает при снижении температуры кристаллизации. При более высокой температуре, вероятно, происходит неполное его осаждение, что ведет к уменьшению выхода целевого продукта. Однако важно отметить, что при отрицательных температурах наблюдается уменьшение температуры начала кристаллизации продукта. Наиболее вероятно, что в этом случае вместе с $\alpha$-терпинеолом происходит кристаллизация и других компонентов, что в конечном итоге приводит к снижению соответствующего показателя. 
Таблица 2. Влияние температуры кристаллизации на количество выделенного $\alpha$-терпинеола и температуру его застывания (продолжительность кристаллизации -10 ч)

\begin{tabular}{c|c|c}
\hline $\begin{array}{c}\text { Температура } \\
\text { кристаллизации, }{ }^{\circ} \mathrm{C}\end{array}$ & $\begin{array}{c}\text { Количество выделенного } \\
\alpha \text {-терпинеола, } \%\end{array}$ & $\begin{array}{c}\text { Температура застывания } \\
\alpha \text {-терпинеола, }{ }^{\circ} \mathrm{C}\end{array}$ \\
\hline 5 & 53,3 & 36 \\
0 & 59,7 & 36 \\
-5 & 60,3 & 32 \\
\hline
\end{tabular}

Наряду с указанными параметрами проведения кристаллизации важным показателем является длительность кристаллизации. В специальных опытах, при температуре $0{ }^{\circ} \mathrm{C}$ была проведена серия опытов при различной длительности кристаллизации (2-10 ч). Полученные результаты представлены в таблице 3.

Из представленных в таблице 3 данных видно, что для повышения выхода $\alpha$-терпинеола продолжительность кристаллизации должно быть не менее 8 ч. Физические свойства полученного таким способом $\alpha$-терпинеола (табл. 4) удовлетворительно согласуются со справочными величинами [19-21].

Как было отмечено выше, $\alpha$-терпинеол и продукты на его основе могут использоваться в качестве дезинфицирующих средств. Для оценки биологической активности полученных продуктов (соснового масла и $\alpha$-терпинеола) на завершающем этапе работы было проведено исследование их бактерицидного и фунгицидного действия. Испытания на фунгицидность и бактерицидность проводили по отношению к отдельным видам микроорганизмов - наиболее активным деструкторам промышленных и полимерных материалов, а также являющимся условно-патогенными, способными вызывать заболевания человека и животных.

Результаты исследований по оценке фунгицидной активности представлены в таблице 5.

Анализ результатов, представленных в таблице 5, показал, что $\alpha$-терпинеол в концентрации 5\% проявляет фунгицидные свойства только по отношению к грибу Candida albicans, $\alpha$-терпинеол в концентрации $10 \%$ фунгициден по отношению к Candida albicans и Penicillium chrysogenum. Сосновое масло с содержанием $\alpha$-терпинеола $80 \%$ (табл. 1) проявляет фунгицидный эффект по всем вышеуказанным микромицетам.

Результаты испытаний препаратов на наличие бактерицидных свойств представлены в таблице 6.

Результаты испытаний показали, что $\alpha$-терпинеол в исследованных концентрациях не обладает бактерицидными свойствами по отношению ко всем тест-культурам бактерий. Сосновое масло обладает слабобактерицидным действием на Staphylococcus epidermidis (диаметр зоны ингибирования роста вокруг образца составлял 14 мм). По отношению к Staphylococcus aureus и Escherichia coli оно проявляет бактерицидные свойства (диаметр зоны ингибирования роста вокруг образца составлял 18 мм и 20 мм, соответственно). По отношению к бактерии Pseudomonas aeruginosa данный препарат не проявил бактерицидности (диаметр зоны ингибирования роста вокруг образца составлял 10 мм).

Таблица 3. Зависимость выхода $\alpha$-терпинеола от продолжительности кристаллизации (температура кристаллизации $0{ }^{\circ} \mathrm{C}$ ).

\begin{tabular}{c|c|c|c|c}
\hline Продолжительность кристаллизации, ч & 4 & 6 & 8 & 10 \\
\hline Выход $\alpha$-терпинеола, $\%$ & 30 & 44 & 62 & 62 \\
\hline
\end{tabular}

Таблица 4. Физические свойства $\alpha$-терпинеола

\begin{tabular}{l|c|c}
\hline \multirow{2}{*}{ Наименование показателя } & \multicolumn{2}{|c}{ Величина показателя } \\
\cline { 2 - 3 } & нормируемое значение & фактически найденное значение \\
\hline Температура застывания, ${ }^{\circ} \mathrm{C}$ & $32-37$ & 33 \\
Плотность при $20{ }^{\circ} \mathrm{C}, \Gamma / \mathrm{cm}^{3}$ & $0,930-0,945$ & 0,9321 \\
Показатель преломления, при $20{ }^{\circ} \mathrm{C}$ & $1,482-1,485$ & 1,4835 \\
\hline
\end{tabular}

Таблица 5. Исследование фунгицидной активности

\begin{tabular}{l|c|c|c}
\hline \multirow{2}{*}{ Виды грибов } & \multicolumn{3}{|c}{ Степень обрастания материала, } \\
& \multicolumn{2}{|c}{ балл / зона ингибирования роста грибов вокруг образца (d, мм) } \\
\cline { 2 - 4 } & $\alpha$-терпинеола 5\% & $\alpha$-терпинеола 10\% & сосновое масло \\
\hline Aspergillus niger & $5 / 0$ & $5 / 0$ & $0 / 27$ \\
Aspergillus amstelodami & $5 / 0$ & $4 / 0$ & $0 / 26$ \\
Penicillium chrysogenum & $4 / 0$ & $0 / 0$ & Нет роста \\
Candida albicans & $0 / 10$ & $0 / 14$ & Нет роста \\
\hline
\end{tabular}


Таблица 6. Исследование бактерицидных свойств

\begin{tabular}{|c|c|c|}
\hline Тест-культура & Диаметр зоны ингибирования, мм & Характеристика препарата \\
\hline \multicolumn{3}{|c|}{$\alpha$-терпинеол $5 \%$} \\
\hline Staphylococcus aureus & 0 & Небактерициден \\
\hline Staphylococcus epidermidis & 0 & Небактерициден \\
\hline Pseudomonas aeruginosa & 0 & Небактерициден \\
\hline Escherichia coli & 0 & Небактерициден \\
\hline \multicolumn{3}{|c|}{$\alpha$-терпинеол $10 \%$} \\
\hline Staphylococcus aureus & 0 & Небактерициден \\
\hline Staphylococcus epidermidis & 0 & Небактерициден \\
\hline Pseudomonas aeruginosa & 0 & Небактерициден \\
\hline Escherichia coli & 0 & Небактерициден \\
\hline \multicolumn{3}{|c|}{$\alpha$-терпинеол $20 \%$} \\
\hline Staphylococcus aureus & 0 & Небактерициден \\
\hline Staphylococcus epidermidis & 0 & Небактерициден \\
\hline Pseudomonas aeruginosa & 0 & Небактерициден \\
\hline Escherichia coli & 0 & Небактерициден \\
\hline \multicolumn{3}{|c|}{ Сосновое масло } \\
\hline Staphylococcus aureus & 18 & Бактерициден \\
\hline Staphylococcus epidermidis & 14 & Слабобактерициден \\
\hline Pseudomonas aeruginosa & 10 & Небактерициден \\
\hline Escherichia coli & 20 & Бактерициден \\
\hline
\end{tabular}

\section{Вbыводы}

Таким образом, проведенные исследования позволили рекомендовать условия для осуществления гидратации скипидара при катализе ортофосфорной кислотой с образованием в качестве целевого продукта монотерпеновых спиртов с высоким содержанием $\alpha$-терпинеола. Анализ биологической активности полученных продуктов показал, что они обладают бактерицидной и фунгицидной активностью по отношению к ряду тест-культур микромицетов и бактерий.

\section{Список литературь}

1. Леса в СССР. В 5 т. Под. ред. А.Б. Жукова. М., 1966. Т. 1. 458 с.

2. Eimer G. A., Díaz I., Sastre E. et al. Mesoporous titanosilicates synthesized from TS-1 precursors with enhanced catalytic activity in the $\alpha$-pinene selective oxidation // Applied Catalysis A: General. 2008. Vol. 343, N1-2. Pp. 77-86.

3. Gaodong Yang, Yong Liu, Zheng Zhou, Zhibing Zhang. Kinetic study of the direct hydration of turpentine // Chemical Engineering Journal. 2011. Vol. 168, N1. Pp. 351-358.

4. Grzona L., Masini O., Comelli N. Deactivation of $\mathrm{H}_{3} \mathrm{PW}_{12} \mathrm{O}_{40} / \mathrm{TiO}_{2}$ catalyst used in the production of camphene // React. Kinet. Catal. Lett. 2005. Vol. 84, N1. Pp. 199-204.

5. Радбиль А.Б. Направления квалифицированного использования скипидара // Химия растительного сырья. 2005. №1. С. 5-11.

6. Исагулянц В.И. Синтетические душистые вещества. Ереван, 1947. 586 с.

7. Дучинская Ю.И., Чебышев А.Г. Производство синтетических душистых веществ. М., 1959. 342 с.

8. Kodzji Minamy, Jutaka Kondo. Synthezis terpinhydrate from $\alpha$-pinene in the presence of emulhators // Misc. Inform. Tokyo Univ. Forests. 1964. Vol. 34, N15. Pp. 9-15.

9. Kullaj S. Determination of optimum conditions for the synthesis of terpin hydrate from terebenthene from Pinus nigra Arn. of Albania // Bul. Shkencave Nat. 1982. Vol. 36, N3. Pp. 59.

10. Патент 79384 (ПНР). Способ получения терпингидрата / J. Kulesza, J. Gora, J. Podlejski. 1975.

11. Радбиль, А.Б., Радбиль Б.А., Золин Б.А. и др. Гидратация камфена, катализируемая гетерополикислотами // Журнал прикладной химии. 2000. Т. 73, №2. С. 241-245.

12. Радбиль, А.Б., Радбиль Б.А., Золин Б.А. и др. Кислотно-каталитические реакции гидратации и алкоксилирования терпеновых углеводородов // Журнал органической химии. 2000. Т. 36, №11. С. 1666-1670.

13. Рудаков Г.А. Химия и технология камфары. М., 1976. 208 с.

14. ГОСТ 21533-76. Продукты лесохимические. Газохроматографический метод анализа. М., 1976. 14 с.

15. Справочник по микробиологическим и вирусологическим методам исследования / под ред. М.О. Биргера. М., 1982. $447 \mathrm{c}$.

16. Бархаш В.А. Неклассические карбокатионы. Новосибирск, 1984. 296 с.

17. Современные проблемы химии карбониевых ионов / под ред. В.А. Коптюга. Новосибирск, 1975. 412 с.

18. Хан В.А., Большакова И.В., Шмидт Э.Н. Терпеноиды живицы Pinus pallasiana // Химия природных соединений. 1984. №1. С. 116-117.

19. Химическая энциклопедия: в 5 т. / под ред. Н.С. Зефирова. М., 1995. Т. 4. 639 с. 
20. Справочник химика / под ред. Б.П. Никольского. Т. 2 Основные свойства неорганических и органических соединений. Л., 1971. 1168 с.

21. Никитин В.М. Химия терпенов и смоляных кислот: монография. Л., 1952. 348 с.

Поступило в редакичию 9 сентября 2014 г. После переработки 9 октября 2014 г.

Radbil' A.B., Dolinskii T.I., Novoselov A.S., Mavrina E.A., Shalashova A.A., Il'ichev I.S., Sulimov A.V., Smirnov V.F., Smirnova O.N. PHYSICAL AND CHEMICAL REGULARITIES OF RECEIVING MONOTERPENIC ALCOHOLS AND ASSESSMENT OF THEIR BIOLOGICAL ACTIVITY

Lobachevsky State University of Nizhni Novgorod, Gagarina ave., 23, Nizhni Novgorod, 603950 (Russia),

e-mail: asulimov@mail.ru

Physical and chemical regularities of synthesis of monoterpenic alcohols by turpentine hydration at a catalysis ortofosforny acid are studied. Influencing of concentration of the catalyst, the water module, temperature and hydration duration on structure and quantity of received products is reviewed. Conditions of obtaining monoterpene alcohols are recommended: the concentration of catalyst aqueous solution $-40 \%$, the temperature $-65{ }^{\circ} \mathrm{C}$, the duration of the synthesis -4 hours, the water module $-1: 1$, the amount of emulsifier $-0,3 \%$ by volume phosphoric acid. Crystallization $\alpha$-terpineol from reaction mixtures with a high content of terpene alcohols studied. Basic physical and chemical characteristics of the products obtained are identified and their fungicidal and bactericidal activity was studied.

Keywords: turpentine, $\alpha$-pinene, $\alpha$-terpineol, hydration, catalysis

\section{References}

1. Lesa v SSSR. [Forests in the USSR]. In 5 vol. Ed. A.B. Zhukov. Moscow, 1966, vol. 1, 458 p. (in Russ.).

2. Eimer G. A., Díaz I., Sastre E. et al. Applied Catalysis A: General, 2008, vol. 343, no. 1-2, pp. 77-86.

3. Gaodong Yang, Yong Liu, Zheng Zhou, Zhibing Zhang. Chemical Engineering Journal, 2011, vol. 168, no. 1, pp. 351-358.

4. Grzona L., Masini O., Comelli N. React. Kinet. Catal. Lett., 2005, vol. 84, no. 1, pp. 199-204.

5. Radbil' A.B. Khimiia rastitel'nogo syr'ia, 2005, no. 1, pp. 5-11. (in Russ.).

6. Isaguliants V.I. Sinteticheskie dushistye veshchestva. [Synthetic fragrances]. Yerevan, 1947, 586 p. (in Russ.).

7. Duchinskaia Iu.I., Chebyshev A.G. Proizvodstvo sinteticheskikh dushistykh veshchestv. [Production of synthetic fragrances]. Moscow, 1959, 342 p. (in Russ.).

8. Kodzji Minamy, Jutaka Kondo. Misc. Inform. Tokyo Univ. Forests., 1964, vol. 34, no. 15, pp. 9-15.

9. Kullaj S. Bul. Shkencave Nat., 1982, vol. 36, no. 3, pp. 59.

10. Patent 79384 (PPR). 1975. (in Polish).

11. Radbil', A.B., Radbil' B.A., Zolin B.A. et al. Zhurnal prikladnoi khimii, 2000, vol. 73, no. 2, pp. 241-245. (in Russ.).

12. Radbil', A.B., Radbil' B.A., Zolin B.A. et al. Zhurnal organicheskoi khimii, 2000, vol. 36, no. 11, pp. 1666-1670. (in Russ.).

13. Rudakov G.A. Khimiia i tekhnologiia kamfary. [Chemistry and Technology of camphor]. Moscow, 1976, 208 p. (in Russ.).

14. GOST 21533-76. Produkty lesokhimicheskie. Gazokhromatograficheskii metod analiza. [State Standard 21533-76. Wood chemical products. Gas chromatographic method for the analysis]. Moscow, 1976, 14 p. (in Russ.).

15. Handbook of microbiological and virological research methods. [Handbook of microbiological and virological research methods]. Ed. M.O. Birger. Moscow, 1982, 447 p. (in Russ.).

16. Barkhash V.A. Neklassicheskie karbokationy. [Nonclassical carbocations]. Novosibirsk, 1984. 296 p. (in Russ.).

17. Sovremennye problemy khimii karbonievykh ionov. [Modern problems of chemistry of carbonium ions]. Ed. V.A. Koptiug. Novosibirsk, 1975, 412 p. (in Russ.).

18. Khan V.A., Bol'shakova I.V., Shmidt E.N. Khimiia prirodnykh soedinenii, 1984, no. 1, pp. 116-117. (in Russ.).

19. Khimicheskaia entsiklopediia. [Chemical Encyclopedia]. In 5 vol. Ed. N.S. Zefirov. Moscow, 1995, vol. 4, 639 p. (in Russ.).

20. Spravochnik khimika. T. 2. Osnovnye svoistva neorganicheskikh i organicheskikh soedinenii. [Reference chemist. Vol. 2. Basic properties of inorganic and organic compounds.]. Ed. B.P. Nikol'skii. Leningrad, 1971, 1168 p. (in Russ.).

21. Nikitin V.M. Khimiia terpenov i smolianykh kislot. Monografiia. [Chemistry of terpenes and resin acids. monograph]. Leningrad, 1952, 348 P. (in Russ.).

\footnotetext{
* Corresponding author.
} 